\title{
Personas con diversidad funcional y fomento del envejecimiento activo a través de la mediación artística. Un estudio de caso
}

People with functional diversity and promoting active ageing through artistic mediation. A case study

\author{
Volumen 21, Número 2 \\ Mayo - Agosto \\ pp. 1-29
}

Catalina Guerrero Romera

Cristina Alonso Molina

\section{Citar este documento según modelo APA}

Guerrero Romera, Catalina., y Alonso Molina, Cristina. (2021). Personas con diversidad funcional y fomento del envejecimiento activo a través de la mediación artística. Un estudio de caso. Revista Actualidades Investigativas en Educación, 21(2), 1-29. Doi. 10.15517/aie.v21i2.46820 


\title{
Personas con diversidad funcional y fomento del envejecimiento activo a través de la mediación artística. Un estudio de caso
} People with functional diversity and promoting active ageing through artistic mediation. A case study

\section{Catalina Guerrero Romera ${ }^{1}$ Cristina Alonso Molina ${ }^{2}$}

\begin{abstract}
Resumen: La atención a las personas mayores con discapacidad intelectual o en proceso de envejecimiento es uno de los desafíos sociales actuales. Este artículo tiene como finalidad analizar la percepción del personal de atención directa de un centro de día de personas con discapacidad intelectual de la Región de Murcia (España), sobre la utilización de la mediación artística o la educación a través del arte. Se trata de un estudio de caso que ha utilizado una metodología de carácter mixto, que combina instrumentos como la entrevista y el cuestionario, con un enfoque de carácter exploratorio y descriptivo. El cuestionario ha consistido en una escala de respuesta tipo Likert. Asimismo, se ha analizado, de forma cualitativa, la información obtenida mediante la realización de entrevistas. Los resultados muestran que la totalidad de las personas encuestadas considera el arte como una herramienta imprescindible para la intervención socioeducativa y, especialmente, para fomentar el enriquecimiento personal, las habilidades sociales y la autonomía. Asimismo, perciben que el uso de esta metodología también plantea dificultades para la intervención como pueden ser la adaptación y el diseño de las actividades a las necesidades de las personas destinatarias o la necesidad de tener una formación específica. No obstante, creen que es un instrumento de gran potencial para la mejora de la calidad de vida y el fomento de un envejecimiento activo. En definitiva, el artículo permite reflexionar sobre las concepciones, oportunidades y desafíos de la mediación artística en el fomento del envejecimiento activo de las personas con bajo desempeño funcional a nivel intelectual como grupo especialmente vulnerable.
\end{abstract}

Palabras clave: educación artística, discapacidad intelectual, envejecimiento, calidad de vida.

Abstract: The care of older people with intellectual disabilities or in the process of ageing is one of the current social challenges. The aim of this article is to analyse the perception of the professionals of a day centre, which cares for people with intellectual disabilities in the Region of Murcia (Spain), on the use of artistic mediation or education through art in the intervention. This is a case study that has used a mixed methodology, combining instruments such as the interview and the questionnaire, with an exploratory and descriptive approach. The questionnaire consisted of a Likert-type response scale. The information obtained through interviews was also analysed qualitatively. The results show that all the people surveyed consider art to be an essential tool for socio-educational intervention and, especially, for promoting personal enrichment, social skills and autonomy. They also perceive that the use of this methodology also poses difficulties for intervention, such as the adaptation and design of activities to the needs of the target group or the need for specific training. However, they believe that it is an instrument with great potential for improving quality of life and promoting active ageing. In short, the article allows us to reflect on the conceptions, opportunities and challenges of artistic mediation in the promotion of active ageing of people with low functional performance at an intellectual level as a particularly vulnerable group.

Key words: artistic education, intellectual disability, ageing, quality of life.

\footnotetext{
1 Profesora Investigadora de la Universidad de Murcia, Murcia, España. Doctora en Filosofía y Ciencias de la Educación. Dirección electrónica: cgromera@um.es Orcid: https://orcid.org/0000-0001-6080-1676

2 Educadora Social de la Asociación para la Atención de Personas con Trastorno del Desarrollo (ASTRADE), Murcia España. Dirección electrónica: cristina.alonso4@um.es Orcid https://orcid.org/0000-0001-5162-7426
}

Artículo recibido: 30 de noviembre, 2020

Enviado a corrección: 24 de marzo, 2021

Aprobado: 19 de abril, 2021 


\section{Introducción}

En el último siglo la sociedad ha experimentado grandes y acelerados cambios en todos sus ámbitos. Una de las transformaciones más significativas ha sido la evolución demográfica y, consigo, el cambio en la estructura poblacional (Fernández-Ballesteros, 2011). La pirámide en la que se veía reflejada la población de hace años, hoy día se ha invertido. En ella se observa el notable crecimiento de la población mayor de 65 años y su longevidad, junto a otras características, como la baja tasa de natalidad (Instituto de Mayores y Servicios Sociales, IMSERSO, 2019). Estos cambios han supuesto la articulación de numerosas acciones y planes gerontológicos que tratan de responder a un aumento de la población mayor y al desafío social que conlleva. Ante esta mayor demanda se requiere incrementar los recursos necesarios para una adecuada atención.

Asimismo, en las últimas décadas se ha producido un aumento del número de personas con bajo desempeño funcional a nivel intelectual como grupo especialmente vulnerable. En este artículo se van a utilizar los términos de discapacidad intelectual y diversidad funcional considerando los nuevos enfoques de la discapacidad y una nueva forma de entenderla, desde los presupuestos de la filosofía de vida independiente (Palacios y Romañach, 2006). No obstante, el término de diversidad funcional es relativamente reciente y aún existen controversias sobre su utilización. En cualquier caso, a lo largo de este trabajo se parte de una concepción positiva en la consideración de las personas, que centre su atención en la dignidad humana, la autonomía y la libertad personal para el fomento de una inclusión social (Palacios y Romañach, 2006).

Los avances científicos de los últimos años, que han beneficiado la esperanza de vida de la población, también lo han hecho en las personas con diversidad funcional. Estos han tenido un importante papel la prevención y tratamiento de las distintas patologías asociadas a la discapacidad. Según los expertos, este envejecimiento se suele situar en torno a los 60 o 65 años de edad. Este no es el caso de las personas con discapacidad intelectual, ellas presentan un envejecimiento prematuro y se considera éste a partir de los 45 o 50 años de edad (Berjano y Burgos, 2009). La Encuesta sobre Discapacidades Deficiencias y Estado de Salud del Instituto Nacional de Estadística (INE) de 1999 afirmaba que uno de cada tres españoles. a partir de los 65 años de edad, presentaba algún tipo de discapacidad. Estudios más recientes indican un incremento considerable de esta población. Con base en los datos, el $18 \%$ del total de las personas con discapacidad intelectual de España tienen más de 45 años de edad (IMSERSO, 2019). 
Al envejecer, las personas con discapacidad intelectual presentan una "segunda discapacidad" (Comité Español de Representantes de personas con Discapacidad [CERMI], 2012), ya que se suman los problemas de la edad a los ya existentes, suponiendo o agravando situaciones de dependencia y convirtiendo a este colectivo en un grupo con mayor vulnerabilidad. Además, por tratarse de un fenómeno relativamente reciente, este envejecimiento es bastante desconocido por la sociedad y aún impera una imagen social de estas personas como la de niños que precisan de educación especial (Pérez, 2002), lo cual les aleja de la oportunidad de tomar decisiones propias y desarrollar su autonomía y responsabilidad.

Es necesario preparar el futuro de las personas con discapacidad intelectual fomentando su autonomía, contando con su opinión y permitiéndoles la participación directa en su proceso de envejecimiento. Para conseguirlo es imprescindible la toma de conciencia a la que nos invita Amor (2009, p.77) con su reflexión sobre la diferencia entre "vida plena" y "vida plana". Este autor considera que se ha de contribuir a desarrollar vidas plenas para lo cual es imprescindible eliminar los estereotipos sociales, tanto los que hacen referencia a la vejez, como los que apelan a su incapacidad de decisión y perpetúan su visión infantil.

Existen asimismo numerosos autores que describen los cambios que experimentan las personas mayores con discapacidad o en proceso de envejecimiento, tanto en el ámbito biológico como psicosocial (Guerrero, 2010; Navas, Uhlmann y Berástegui, 2014; Madrigal, 2007; Berjano y García, 2009). En consecuencia, teniendo en cuenta estas tendencias y cambios, y con la finalidad de fomentar un envejecimiento lo más activo y saludable posible, se ha de proporcionar una oferta de servicios y programas adecuada y adaptada a sus necesidades, así como una atención a los procesos de transición a la etapa de la vejez, a partir de las directrices marcadas por la Organización Mundial de la Salud sobre el envejecimiento y la salud (OMS, 2012).

Igualmente, existen numerosos estudios que consideran que el envejecimiento puede ser favorecido a través de la realización de actividades relacionadas con el arte, o a través del arte, para la mejora de la calidad de vida y bienestar, y para potenciar la autonomía, el desarrollo socioemocional y la participación e inclusión social (De Miguel Badesa, 2006; Ballesta, Mesas y Vizcaíno, 2011; Morón, 2012; Guerrero, 2015; Alonso, 2016). El arte, además, se considera una herramienta fundamental para promover los derechos sociales, la igualdad de oportunidades y el desarrollo sostenible en la medida en que es una forma de expresión y comunicación que permite afrontar los actuales desafíos y "apostar por la 
transformación social y el desarrollo de valores democráticos y comprometidos con una sociedad mejor para todos" (Guerrero, 2015, p. 7).

A partir de estas premisas, la investigación planteada parte de la hipótesis de que la intervención a través del arte puede aportar beneficios en la mejora de la calidad de vida y en el desarrollo de un envejecimiento más pleno.

Es por ello que el objetivo general de la investigación es analizar la percepción del personal de atención directa acerca de la importancia del arte en la intervención social. Los objetivos específicos son:

1. Examinar el nivel de conocimiento y de formación que tienen sobre la utilización de la metodología de la mediación artística como herramienta de intervención para la mejora de la calidad de vida y en la promoción del envejecimiento activo.

2. Estudiar su percepción sobre los beneficios o ventajas de la utilización de esta metodología.

\section{Referentes teóricos}

\subsection{La calidad de vida y el envejecimiento de las personas con discapacidad intelectual}

El proceso de envejecimiento conlleva cambios físicos, cognitivos y socioemocionales para las personas con discapacidad intelectual. Estos cambios pueden suponer declives 0 empeoramientos en su calidad de vida que exigen atención (Guerrero, 2010; Navas, Uhlmann y Berástegui, 2014).

Para Schalock y Verdugo (2003), la calidad de vida se entiende como el reflejo de las condiciones de vida deseadas por una persona en relación con ocho necesidades fundamentales: bienestar físico, bienestar material, bienestar emocional, derechos, autodeterminación, inclusión social, relaciones interpersonales y desarrollo personal. Para lograr un envejecimiento de calidad en las personas con discapacidad, Navas et al. (2014, p. 11) destacan que los principios de actuación se deben centrar en "potenciar su inclusión en la comunidad, su autodeterminación y en que reciban el máximo apoyo familiar".

Entre los distintos factores de riesgo, que amenazan la calidad de vida de las personas con discapacidad intelectual, cabe hacer especial mención de la sobreprotección y dependencia. Como bien advierte Etxeberría (2005), es muy usual que familiares y profesionales tiendan a la sobreprotección de estas personas evitando, en muchos casos, la vivencia directa de experiencias negativas como la muerte o enfermedad. De esta manera, se 
consigue un estado de infantilización permanente, que genera una enorme inmadurez emocional y niega la oportunidad de tomar decisiones propias y conseguir una autonomía y responsabilidad que aleje a estas personas de la dependencia y les permita un desarrollo íntegro.

Para hacer frente al nuevo desafío que supone el envejecimiento activo, se están ofreciendo respuestas desde este paradigma: la Planificación Centrada en la Persona (PCP). Carratalá (2012) define la PCP como el resultado de un movimiento por la inclusión social, articulado en los principios de normalización y reformulados en la revalorización del rol social. Para implantar este enfoque es necesario desmontar visiones tradicionales donde la intervención social se encontraba centrada en poner etiquetas a partir de diagnósticos que describían déficits y necesidades de este colectivo. Ello sitúa la toma de decisiones en los expertos, enfatizando las desigualdades mediante los servicios sociales, empeñados en dar respuesta a supuestas necesidades colectivas de una manera impersonal y burocratizada, sin atender los intereses de las personas atendidas.

En este sentido, no debemos perder de vista el gran obstáculo que suponen los estereotipos a la hora de afrontar la inclusión y el envejecimiento activo de las personas con diversidad funcional. Muchas concepciones estereotipan la vejez como una etapa deficitaria en la que a medida que se va cumpliendo edad, se van perdiendo capacidades. Moreno (2010) explica como de esta manera se abre paso el concepto de "edadismo", acuñado por Butler ya en 1969 para referirse a la atribución de determinados estereotipos hacia las personas, exclusivamente por el hecho de tener una edad avanzada. Losada (2004), nos traslada que dichos estereotipos conducen a que las propias personas mayores asuman esas creencias, se sientan dependientes y por ende vean reducidas sus oportunidades de participación social. El Informe Helduakadi sobre Estereotipos asociados a las Personas Mayores (2014, p. 17) señala el "edadismo como la tercera forma de discriminación de nuestra sociedad, tras el racismo y el sexismo".

Ya la II Asamblea Mundial sobre el Envejecimiento en el año 2002 llamó la atención sobre que las personas mayores no son una carga para la sociedad moderna, son un activo que aporta experiencia, formación, valores humanos, tiempo libre, dedicación y apoyo a su familia. Por tanto, son generadores de actividad, de consumo, de calidad de vida, de desarrollo de nuevos recursos económicos y sociales. Guerrero (2010) afirmó que el envejecimiento debe verse como una etapa en la que también es posible el desarrollo de las capacidades de los hombres y las mujeres, como agentes activos de nuestras sociedades, en las que deben seguir 
participando como ciudadanos y ciudadanas de pleno derecho, con el pleno reconocimiento social.

Afortunadamente en estos últimos años se están dando importantes pasos desde el marco político. Si se quiere hacer del envejecimiento una experiencia positiva, una vida más larga debe ir acompañada de oportunidades continuas de salud, participación y seguridad. La Organización Mundial de la Salud (OMS, 2002) utiliza el concepto "envejecimiento activo" para responder a dichos objetivos, definiéndolo como el proceso de optimización de las oportunidades en relación con la salud, la participación y la seguridad para mejorar la calidad de vida a medida que se envejece.

El envejecimiento activo, también llamado "envejecimiento con éxito" (CERMI, 2012), es considerado un concepto multidimensional que abarca, trasciende y supera la buena salud y que está compuesto por un amplio conjunto de factores bio-psicosociales. Para FernándezBallesteros (2011), los criterios para identificar esta forma de envejecer son las condiciones de salud, el funcionamiento físico y cognitivo óptimo, el afecto positivo y la participación social. Para Pinazo y Sánchez (2005), el envejecimiento activo es la forma de implicarse activamente en la vida, lo que significa mantener unas relaciones sociales satisfactorias y una actividad productiva (retribuida o no) que contribuya a la mejora personal y/o a la mejora de la comunidad e implique un esfuerzo personal.

Si bien es cierto que en los últimos años se ha producido en España un incremento de publicaciones e investigaciones orientadas a identificar las necesidades de este colectivo, así como líneas de actuación, las administraciones y organizaciones han de garantizar el diseño y puesta en marcha de distintos programas destinados a promover la salud de las personas mayores con discapacidad intelectual, así como su desarrollo personal. Se deben proporcionar, entre otras, oportunidades de ocio sin generar, en medida de lo posible, servicios específicos que contribuyan a la segregación. Cabe destacar que la mediación artística puede ser una herramienta muy potente para conseguir dichos objetivos.

\subsection{Beneficios de la mediación artística y envejecimiento activo}

Existen numerosos autores que investigan los procesos de simbolización y desarrollo humano, así como sobre la capacidad transformadora de la experiencia artística. Ros (2010, p. 4) afirma que "todos los seres humanos poseemos capacidad para la creación" y MartínezSalanova (2014) defiende que la creatividad no es patrimonio único de los artistas, sino que nos atañe a todos. Carrascal y Solera (2014) sostienen que esta capacidad es innata y no 
caduca. Ballesta et al. (2011) citan los escritos de Dubuffet (1947) en los que se recoge por primera vez la idea que expone Martínez-Salanova, y en la que se alega que todo ser humano por encima de sus capacidades o al margen de su razón puede ser tan poderoso artísticamente como cualquier otro artista reconocido. Dubuffet fundó la compañía del Art Brut. Esta compañía recogía producciones artísticas realizadas por personas que poco tienen que ver con los artistas convencionales, la mayoría de ellas tenían discapacidad intelectual o algún tipo de trastorno mental, así como presos, amas de casa, niños o niñas. Todos ellos comparten un desinterés económico por su trabajo y se expresan libremente, ajenos a convencionalismos y gustos sociales de su época. Cardinal (1972, cit. en Ballesta et al., 2011) explica que el Art Brut pasó a denominarse Arte Outsider y dio paso al establishment del Arte a las personas con discapacidad. Desde ese momento fueron varios los artistas con discapacidad que ganaron fama por sus obras, podemos destacar a la norteamericana Judith Scott, que tuvo su reconocimiento internacional como escultora después de vivir 36 años en una institución psiquiátrica. Judith tiene síndrome de Down y es sordomuda, su historia hecha película inspiró un colectivo artístico, pionero en nuestro país, llamado "Debajo del sombrero" que se define como "una plataforma para la creación, investigación, producción, y difusión de arte donde sus principales protagonistas son las personas con discapacidad intelectual” (Alonso, 2016, p. 245).

Igualmente, son muchas las asociaciones y proyectos que promueven la mediación artística y el papel del arte como herramienta comunicativa en las personas con discapacidad intelectual alrededor del mundo, así como medio para reivindicar el derecho a ser uno mismo (Alonso, 2016). Según Ballesta et al. (2011), el arte como proceso humano y sus medios son posibilitadores de espacios para la igualdad, la visibilidad y la normalidad, así como para la expresión de emociones, la comunicación y el diálogo.

En el arte, por tanto, no debe de existir marginación en la expresión, hay lenguajes para todas las culturas e individuos y los modos de expresión se relacionarán con las propias capacidades (Martínez-Salanova, 2014). De la misma forma que es necesaria la creatividad y su ejercicio por parte de todos los individuos, independientemente de sus capacidades. Sabemos pues, que todos tenemos la capacidad creadora, pero la misma dependerá de las oportunidades que tengamos para poder expresarlo. Así Curtis, Demos y Torrance (1978, cit. en Ballesta et al., 2011) consideran la creatividad como una posibilidad dada a todos los seres humanos al nacer, pero que, con frecuencia, se pierde, se entierra o se inhibe por los efectos del proceso cultural o por situaciones de vulnerabilidad o dificultad social. En este sentido, 
Calderón (2014) afirma que las personas con discapacidad están ávidas de ser escuchadas y reconocidas en sus interpretaciones, luchas y reclamos. Estas personas "constituyen un colectivo cosificado por el resto, especialmente por los profesionales: personas al ser nombradas por otras se convierten en cosas (con ceguera, parálisis, síndromes...) y quedan encarceladas en las palabras" (Calderón, 2014, p. 44). La expresión artística permite romper con dicha cosificación, ya que ofrece la posibilidad de una participación radical: la expresión incondicional de uno mismo, más allá de las limitaciones del lenguaje y la etiquetación.

Con relación a la inclusión de personas con discapacidad, Botero (2014) afirma que la comunicación y la expresión artística cumplen dos papeles diferenciados pero esenciales al mismo tiempo en la búsqueda de este propósito: 1) el de ser agentes de socialización que crean y configuran los paradigmas de comprensión de la discapacidad y que fomentan estilos de vida asociados a ella; y 2) ser espacios legítimos de expresión de y para las personas con discapacidad y sus comunidades.

En el primer caso, la labor de la comunicación y la expresión artística es la puesta en marcha de estrategias de sensibilización, información y formación en torno a la discapacidad y a las personas con discapacidad, que contribuyan a la eliminación de los prejuicios y estereotipos que aún circulan en la sociedad respecto a estas personas y sus comunidades. En el segundo, la labor a desarrollar es la creación de más y mejores espacios de comunicación y de expresión artística que posibiliten la participación y la igualdad de oportunidades y en donde se respete su independencia y autonomía.

La estimulación artística consigue fomentar las capacidades básicas de atención y concentración en las personas mayores, además de mejorar su comunicación con el entorno, y la conexión con sus capacidades creativas personales. El simple hecho de mostrarles piezas musicales o proporcionarles papel y pinturas para que expresen libremente su creatividad, está consiguiendo que se mantengan activas y que mejore su relación con el entorno. Carrascal y Solera (2014) afirman que es importante mantener en las personas mayores la plasticidad del cerebro de un niño, capaz de absorber ideas, aprender un nuevo lenguaje, comunicarse e imaginar.

Desde el espacio que facilita la mediación artística puede favorecerse una imagen positiva del envejecer, que no debe significar únicamente una prolongación de la vida, sino conseguir que esta etapa sea saludable, autónoma y activa socialmente (Guerrero y Martínez, $2013,2017)$. En este sentido, son muchos los beneficios de la mediación artística en la vejez y de cómo ésta ayuda a lograr el envejecimiento activo. 
Ramírez (1999) presentó una serie de enfoques acerca de la experiencia artística en la vejez entre los que se encontraban el enfoque terapéutico. Este enfoque utiliza el arte como terapia en personas mayores que sufren aislamiento, soledad, depresiones y demencias o enfermedades ligadas a la edad y el enfoque cultural y entiende el arte como espacio para revalorizar socialmente a las personas mayores.

La mediación artística reconoce distintas características de estos enfoques, que pueden estar encaminadas hacia el logro de un envejecimiento activo. Se parte de un concepto por tanto que propone la utilización de los diferentes lenguajes artísticos y culturales para la intervención educativa,

La Educación a través del arte supondría la utilización de los distintos lenguajes artísticos y culturales para activar potencialidades, capacidades, talentos y recursos de las personas y de los entornos. Una intervención educativa cuya finalidad es lograr y facilitar cambios y mejoras, así como establecer o activar itinerarios para la transformación, que promocionen además la inclusión social de los grupos más vulnerables o en riesgo de exclusión. (Guerrero, 2015, p. 7)

Las actividades artísticas, en este sentido, han de ayudar a las personas mayores a mejorar su afectividad, a expresarse emocionalmente redescubriéndose a sí mismas, a promover nuevas relaciones sociales (especialmente aquellas de carácter intergeneracional), a salir de su monotonía y mejorar su autoestima gracias al aumento de confianza y a la posibilidad de poder controlar la actividad que realizan, así como a mejorar su bienestar físico y la prevención de enfermedades (Rico, 2010).

Cabe destacar que la concienciación que debe acompañar a las personas mayores en cuanto a su capacidad de desarrollo personal y enriquecimiento durante la etapa final de sus vidas, debe ser a su vez social. Se deben promover para ello iniciativas educativas que se adecúen a este colectivo, que refuercen las posibilidades de crecimiento, la autoestima y el sentimiento de utilidad; y eliminen los estereotipos de la vejez y las visiones negativas que generan, en su mayoría, fuertes barreras mentales que impiden a las personas mayores creerse capaces de realizar actividades y acercarse a la experiencia artística. El arte, por tanto, puede convertirse en un potente vehículo para la inclusión social y el desarrollo socioafectivo, que fomenta un rol protagonista de las personas y promueve el desarrollo de cambios.

La expresión artística permite romper con el etiquetaje de las personas mayores con discapacidad intelectual. Desde el espacio que facilita la mediación artística puede favorecerse 
una imagen positiva del envejecer, que no debe significar únicamente una prolongación de la vida, sino conseguir que esta etapa sea, como se ha mencionado, saludable, autónoma y activa socialmente.

La investigación se fundamenta así en las concepciones o enfoques de una educación por el arte o a través del arte (Read, 1991; Eisner,1995; Pérez, 2002; Guerrero, 2015) y en el modelo de mediación artística propuesto por Moreno (2016). Este último modelo defiende que el arte es una herramienta en la medida de que facilita una experiencia al margen de los resultados y que posibilita el desarrollo integral de la persona. Es decir, lo que más interesa no es si la obra producida es de mayor o menor calidad técnica o estética, sino su desarrollo, recuperando de esta manera algunos conceptos abordados desde la pedagogía, psicología y educación social: desarrollo integral de la persona y de sus potencialidades, elaboración simbólica y superación de conflictos inconscientes, tomar conciencia de la situación e iniciar un proceso de transformación y reinserción (Moreno, 2010).

Desde esta investigación se entiende la mediación artística a partir un paradigma que reconoce características de distintos enfoques encaminados hacia el logro de un envejecimiento activo y la mejora de su bienestar.

Cabe destacar que la concienciación que debe acompañar a las personas mayores con diversidad funcional en cuanto a su capacidad de desarrollo personal y enriquecimiento durante la etapa final de sus vidas, debe ser a su vez social. Para ello es necesario promover iniciativas educativas adecuadas que refuercen sus posibilidades de crecimiento, la autoestima y el sentimiento de utilidad. El arte se convierte, por tanto, en un potente vehículo para la intervención.

Por otra parte, a la hora de hablar sobre mediación artística o educación a través del arte, no se debe caer en el error de confundirlas con el concepto de arteterapia, pese a que sea un punto de referencia para la mediación artística, en tanto que su objetivo no es la producción artística en sí, sino los procesos que se generan durante la experiencia artística y ayudan a la transformación personal de los participantes. Sin embargo, Moreno (2010) considera que la arteterapia conlleva aspectos más clínicos y sus profesionales deben tener una formación específica, ya que intentan dar respuesta e interpretar enfermedades, en muchas ocasiones, psicológicas, utilizando el arte como herramienta para lograrlo. De esta manera, desde la arteterapia no se pretende el aprendizaje de conocimientos artísticos, ni siquiera la inserción social de la persona, ya que el objetivo es la mejora de su vida psíquica (Moreno, 2010). 


\section{Metodología}

\subsection{Enfoque}

En la investigación se ha optado por un enfoque exploratorio y descriptivo de carácter mixto para poder conocer una perspectiva más precisa del objeto de estudio. Se trata de un estudio de caso que usa dos métodos distintos que permiten considerar diversas fuentes y tipos de datos y mostrar la realidad desde dos perspectivas: la cualitativa tendrá en consideración la percepción más subjetiva de las personas profesionales del centro seleccionado a través de la entrevista, y la cuantitativa, con la utilización de un instrumento concretamente tipo encuesta a través del diseño de un cuestionario de elaboración propia y sometido a un proceso de validación por expertos.

\subsection{Unidades de análisis}

El soporte metodológico del trabajo responde a un estudio de casos, ya que el objetivo principal del mismo es comprender la particularidad de una realidad concreta. La investigación tiene un marcado carácter descriptivo y, por tanto, interesa el contexto en el que se producen los fenómenos de intervención con personas mayores con discapacidad intelectual, y se pone el acento en la observación de los y las profesionales que trabajan la mediación artística en un centro de día de la Región de Murcia (España), con el fin de entrevistar, interpretar y analizar la información obtenida.

Para llevar a cabo la investigación desde un punto de vista metodológico particularista y descriptivo, se realizó una identificación de la población o contexto y la elección de los participantes según los siguientes criterios de selección: ser un centro que atendiera a personas con discapacidad intelectual mayores de 40-45 años; que el centro contase con una oferta interna de talleres que trabajaran la mediación artística o realizaran actividades educativas a través del arte; y que las personas seleccionadas tuviesen experiencia en este ámbito. El centro seleccionado tenía así un aula específica de personas mayores con discapacidad intelectual y además participaba en un proyecto en colaboración con la Universidad de Murcia durante los años 2015-2016.

El centro tiene como finalidad fomentar el desarrollo de la autonomía de estas personas a través de distintos programas de intervención que ponen en práctica actividades de la vida diaria, el desarrollo de la vida comunitaria, el mantenimiento y rehabilitación física, la realización de actividades ocupacionales, destrezas de autocuidado y habilidades sociales y personales. 
Igualmente, se obtuvo el consentimiento informado y un compromiso de confidencialidad de todas las personas participantes.

En cuanto a los datos de las personas participantes, han sido solamente seleccionadas las seis personas del centro que atienden un grupo de personas mayores o en proceso de envejecimiento y con cierto conocimiento y práctica en la metodología de la mediación e intervención a través del arte.

En relación al sexo, en su mayoría han sido mujeres (cinco participantes) y solo un participante era hombre. Respecto a las edades, dos de las personas se situaban entre los 31 y los 40 años, otras dos eran mayores de 51 años de edad, siendo menor de 30 años sólo una y entre los 41 y los 50 años de edad otra de ellas. En cuanto a su titulación 4 tenían estudios universitarios y el resto cualificación profesional. De forma específica, 3 eran educadores sociales, y los demás perfiles profesionales se correspondían con enfermería, pedagogía y psicología. Las funciones que desempeñaban dentro del centro eran variadas: enfermería, dirección y gestión, docencia y formación.

En relación a los años de experiencia, dos de las personas participantes llevaban menos de cinco años trabajando; una tenía una experiencia de entre 6 y 12 años trabajados; dos contaban con una experiencia de entre 12 y 20 años; y otra tenía más de 20 años de experiencia profesional con este colectivo.

\subsection{Técnicas de recolección}

Respecto a los instrumentos, el cuestionario utilizado es una escala numérica tipo Likert (1: nada; 2: poco; 3: bastante; 4: mucho) con un total de 30 ítems. Se trata de un instrumento de elaboración propia sometido a un proceso de validación por expertos que lo valoraron de manera positiva y se obtuvieron puntuaciones superiores a tres en la escala Likert. En base a las valoraciones y comentarios planteados por los expertos se elaboró la versión final del cuestionario (anexo 1). Este tiene por objetivo conocer la percepción y necesidades de formación que presentan los distintos profesionales que trabajan con personas mayores con discapacidad intelectual en cuanto a la metodología de la mediación artística y se estructura en tres grandes bloques:

Bloque 1. Conocimiento de la metodología de la mediación artística.

Bloque 2. Beneficios o ventajas de la utilización de la metodología de la mediación artística.

Bloque 3. Necesidades de formación que tienen. 
Además de los distintos ítems que componen cada uno de estos bloques, se presentan unas variables de identificación: sexo, edad, estudios, profesión, localidad, carácter del centro en el que trabaja, función profesional que desempeña y años de experiencia.

Por otra parte, la entrevista responde a un análisis de la perspectiva que tienen las personas encuestadas sobre el uso de la metodología artística. Concretamente, se incluían cuestiones relacionadas con su grado de conocimiento sobre experiencias, talleres 0 actividades que se llevasen a cabo desde enfoques de la mediación artística y el arte, y acerca de las características de esas acciones (diseño y planificación, tipo de actividades, metodología empleada, sistema de evaluación). También se plantearon cuestiones relacionadas con las ventajas e inconvenientes de su puesta en práctica y su valoración acerca de las necesidades de participación o implicación de familiares en las acciones.

\subsection{Procesamiento de análisis}

Los datos obtenidos del cuestionario han sido analizados a través del programa estadístico SPSS versión 19. Respecto a las entrevistas se ha realizado el procedimiento de análisis de datos cualitativo PGADC (Proceso General de Análisis de Datos Cualitativos): reducción de datos, codificación y contabilización de la frecuencia en la que aparecen durante el desarrollo de las entrevistas (Hernández-Pina, Maquilón y Cuesta, 2008).

\section{Resultados}

\subsection{Resultados del análisis de los cuestionarios}

A continuación, se muestran los resultados del análisis del cuestionario. En primer lugar, en relación con los datos del primer bloque: conocimiento y utilización de la metodología de la mediación artística, la valoración de las distintas personas participantes estaba bastante dividida, siendo tres las que dicen conocer y haber empleado dicha metodología, mientras que la otra mitad afirma desconocerla y la ha utilizado poca o ninguna vez durante su experiencia y trayectoria profesional. No obstante, cuatro comentan que han diseñado o participado en actividades que utilizan distintos lenguajes artísticos como pintura, música o danza.

En la Figura 1 se puede observar que el total de las personas participantes afirman que son necesarios y útiles los talleres y/o actividades que trabajan desde la perspectiva artística, así como la existencia de oferta de dichos talleres en su centro de trabajo. También todas ellas están de acuerdo en la prevalencia de la importancia del proceso más que del resultado en la filosofía de los talleres que utilizan el arte como herramienta; cuatro puntúan con un máximo 
de 4 dicha prevalencia, mientras que dos de ellas lo hacen con un 3 sobre 4. La mitad de las personas participantes cree que para trabajar o participar en actividades de mediación artística, se precisa de unas dotes artísticas mínimas y cierto conocimiento sobre el arte, mientras que la otra mitad opina que es poco relevante.

Figura 1

Conocimiento de la metodología de la mediación artística

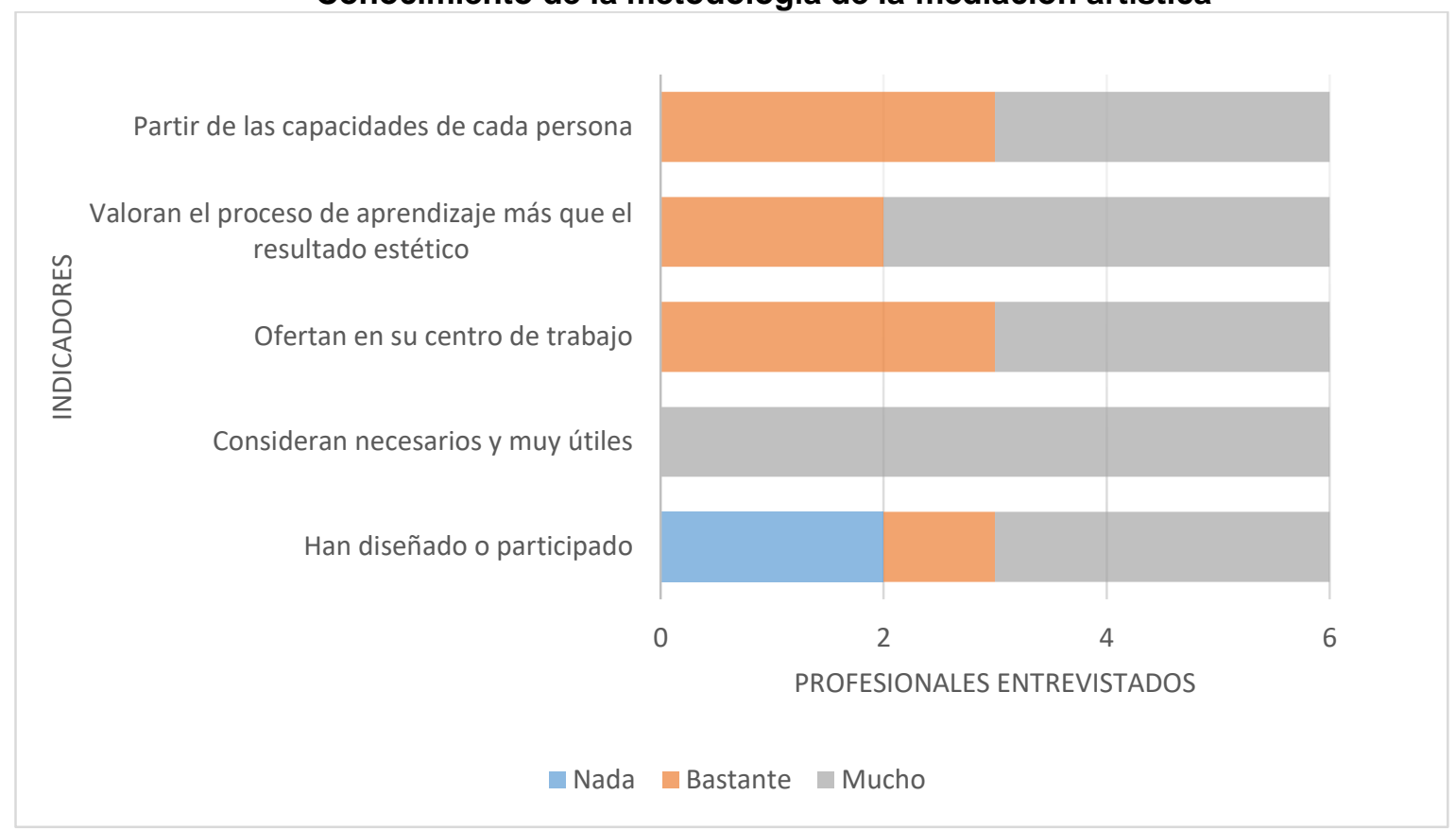

Fuente: Elaboración propia, 2016

En cuanto a los datos del segundo bloque sobre beneficios o ventajas de la utilización de la metodología de la mediación artística, todas las personas encuestadas consideran que la metodología de la mediación artística o la utilización del arte es una herramienta adecuada para trabajar el desarrollo de personas con discapacidad intelectual, cinco la estiman como muy adecuada y una como bastante adecuada.

Igualmente, cinco de ellas consideran las habilidades sociales un punto clave en el desarrollo de las personas y puntúa con un máximo de 4 en la escala Likert la mediación artística como herramienta para fomentarlas. Del mismo modo, cinco personas consideran la participación social como un factor importante a la hora de determinar la calidad de vida de las personas mayores con discapacidad intelectual.

La metodología de la mediación artística es considerada por las personas encuestadas como un excelente vehículo de comunicación que favorece la expresión, cinco de ellas la 
valoran con un 4 sobre 4, el mismo porcentaje opina que dicha metodología aporta grandes beneficios en el desarrollo de la autonomía de las personas con discapacidad intelectual. Por otra parte, cinco de ellas defienden como factores determinantes en el desarrollo de estas personas tanto las habilidades sociales como la participación, considerando que la metodología de la mediación artística es una excelente herramienta para lograrlas, además de favorecer la expresión y aportar grandes beneficios en su autonomía.

Por otra parte, todas las personas encuestadas creen que la metodología de la mediación artística puede ayudar a fomentar un envejecimiento activo, así como la consideran adecuada para trabajar con personas mayores con discapacidad intelectual. Asimismo, el total de las personas encuestadas afirma que contribuye a la mejora de la calidad de vida y del bienestar, y afirman además que esta metodología es muy pertinente para favorecer y potenciar el desarrollo emocional.

En relación con la valoración que tiene esta metodología dentro del ámbito educativo y social, la mitad de las personas encuestadas afirma que está poco valorada, mientras que la otra mitad cree que sí se encuentra bastante valorada (dos personas) y muy valorada (una persona).

En cuanto al tercer y último bloque analizado, sobre necesidades de formación, una de las personas encuestadas considera que cuentan con nada o poca formación específica (una y tres personas respectivamente). El mismo porcentaje afirma haber realizado algún tipo de formación en mediación artística o temas relacionados, mientras que solo una de ellas dice no haber recibido nada de formación en este ámbito. No obstante, dos de las personas encuestadas se sienten bastante capacitadas para diseñar y dinamizar talleres que trabajen la metodología de la mediación artística o que utilicen el arte como estrategia para la intervención socioeducativa, y dos de ellas alegan sentirse muy preparadas para ello. Por otro lado, tres se consideran poco capacitadas para dicho desempeño. En cualquier caso, todas las personas encuestadas creen necesaria la formación específica en metodologías de mediación artística. Sin embargo, cuatro de ellas piensan que cualquier perfil profesional puede realizar un taller de mediación artística, mientras que dos creen lo contrario.

Es importante, por tanto, señalar que cuatro de las personas encuestadas que imparten talleres de mediación artística cuentan con muy poca formación específica a pesar de haber recibido alguna formación, lo que indica claramente que dicha formación es insuficiente. Además, la mitad de las personas encuestadas se considera poco capacitada para diseñar y dinamizar talleres que trabajen la metodología de la mediación artística o que utilicen el arte 
como estrategia para la intervención socioeducativa. No obstante, resulta significativo que cuatro personas piensan que cualquier perfil profesional puede realizar un taller de mediación artística (Figura 2).

Figura 2

Necesidades de formación

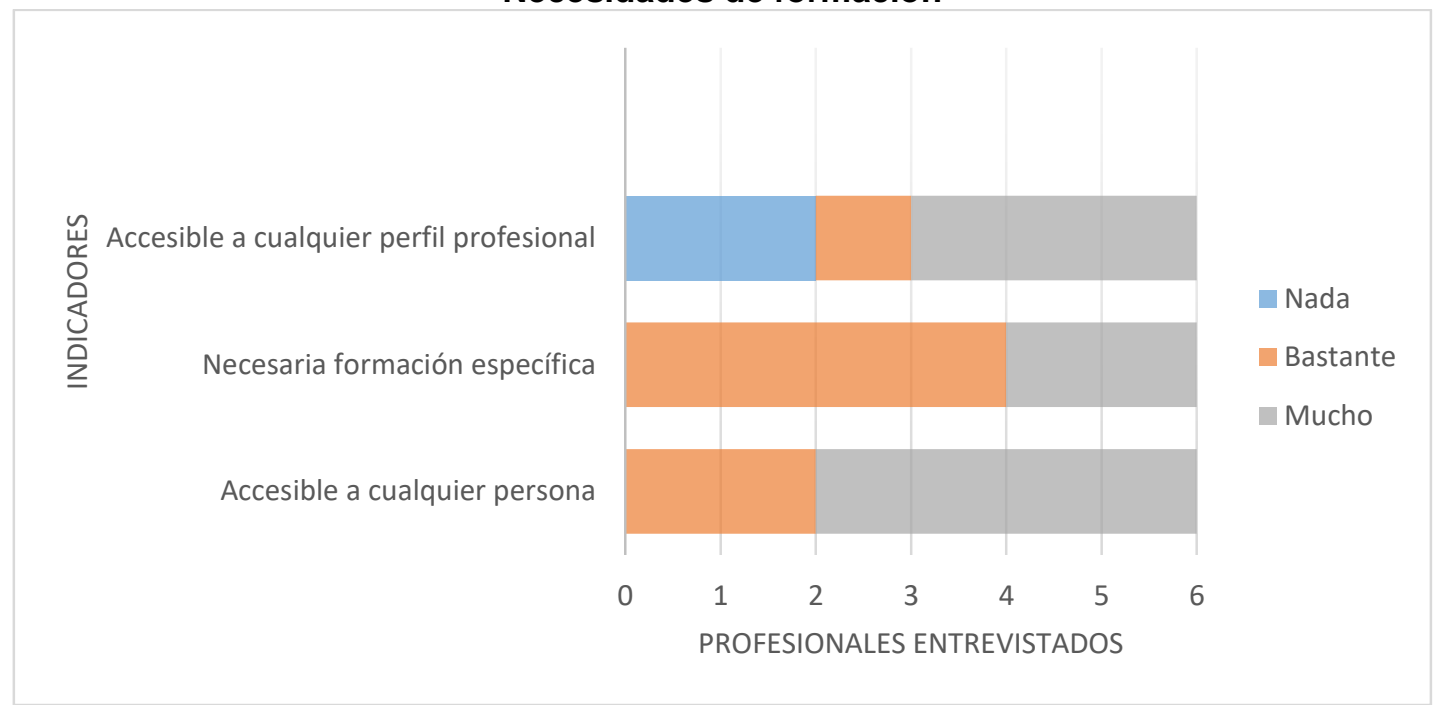

Fuente: Elaboración propia, 2016

Todas las personas encuestadas están de acuerdo en que la mediación artística debería contemplarse en el currículo de carreras universitarias como Educación Social, Pedagogía o Psicología. Por último, destacar que la totalidad de las personas encuestadas afirma que le gustaría recibir formación específica en la metodología de la mediación artística.

\subsection{Resultados del análisis de las entrevistas}

Respecto a los resultados del análisis de las entrevistas, el total de las personas entrevistadas conoce alguna experiencia de taller o intervención relacionada con la mediación artística. Además, todas indican que en su centro de trabajo se han llevado a cabo o se están llevando a cabo, actividades que tienen relación con el arte.

En cuanto a las características de las acciones y actividades llevadas a cabo en este ámbito, en primer lugar en relación con su diseño y planificación, la mitad de ellas lo consideran imprescindible para el buen desarrollo de las mismas, y solo una persona cree que existe diseño en aquellas actividades que se programan de manera externa al Centro.

Sobre el tipo de actividades utilizadas para trabajar la mediación artística, todas las personas encuestadas destacan las relacionadas con la expresión corporal, incluyendo: 
talleres de teatro, interpretación, mímica, baile e incluso la gerontogimnasia o gimnasia adaptada a las personas mayores. Seguidas de las actividades nombradas, las segundas más referenciadas son aquellas que tienen que ver con la expresión plástica o manual, aludiendo a ellas cinco de las personas participantes, aquí citaron pintura, talleres de arcilla y arte floral. Por otro lado, la musicoterapia es uno de los talleres que trabajan la mediación artística en el centro (tres personas han hecho especial mención a esas actividades) y otra de ellas ha hecho referencia a la actividad de cuentacuentos como otra forma de trabajar el arte en el centro. Por otra parte, todas las personas entrevistadas relacionan el arte o la mediación artística con las actividades de expresión corporal, las segundas más nombradas son las de expresión plástica o manual y las actividades relacionadas con la música las referencian tres de las personas entrevistadas.

Respecto a si los y las profesionales del centro son conscientes de la metodología empleada en las distintas actividades que trabajan la mediación artística, solo dos de las personas entrevistadas afirman desconocer dicha metodología o la confunden con las técnicas empleadas a la hora de realizar las distintas dinámicas, no obstante cuatro de ellas consideran que existe una metodología individualizada que desarrolla los programas centrados en la persona (PCP). Dicha metodología es la que vertebra todas las actuaciones que se llevan a cabo en el centro, cuya filosofía es la adaptación individualizada a cada necesidad de la persona con la que se trabaja.

En relación con el sistema de evaluación empleado, se han encontrado variedad de respuestas y desacuerdo. El mismo porcentaje de personas que desconocía la metodología empleada, comparte su postura ante la evaluación, cuatro de ellas sí conocen el sistema de evaluación, pero solo dos están de acuerdo en que esta evaluación es final, es decir, que se lleva a cabo una evaluación genérica de todos los talleres al final del curso y debería existir una especificación mayor de las actividades de evaluación. Por otro lado, una de las personas mantiene la certeza de que existe tanto una evaluación inicial, como una procesual y otra sumativa o final y solo otra afirma que los proyectos externos siempre se evalúan, pero no especifica cómo.

En cuanto a los inconvenientes o dificultades que han destacado a la hora de trabajar la mediación artística con este colectivo, la mitad de las personas entrevistadas está de acuerdo en que las adaptaciones de las actividades a las necesidades que presentan las personas mayores con discapacidad intelectual es uno de los mayores inconvenientes; dos de ellas comparten que los grupos numerosos es otra de las grandes dificultades a la hora de trabajar 
la mediación artística con este colectivo; otras dificultades que señalaron fueron: la poca coordinación interdisciplinar entre profesionales, la falta de dinero para material y la de recursos humanos, el choque con las normas internas de familiares mayores y la falta de formación específica en mediación artística (Figura 3).

Figura 3

Inconvenientes o dificultades de la mediación artística

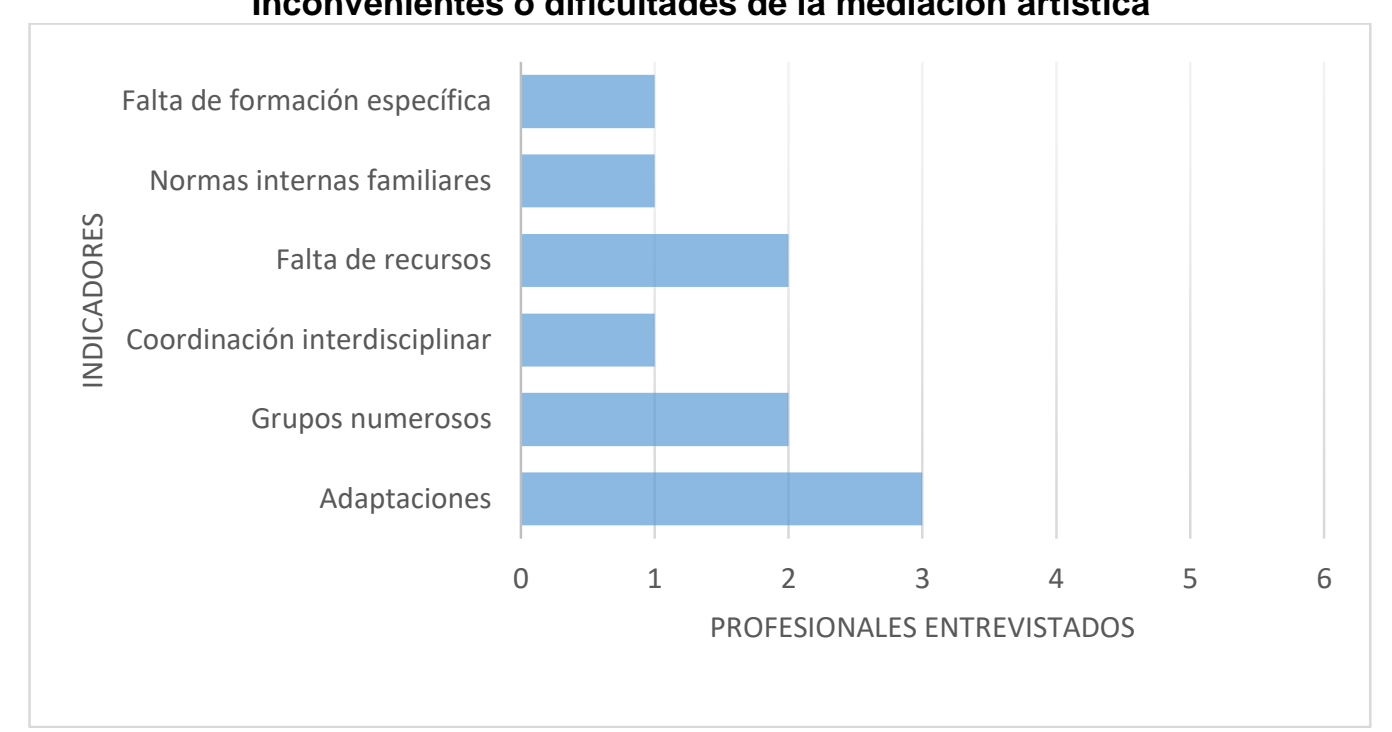

Fuente: Elaboración propia, 2016.

El mayor inconveniente según señalaron la mitad de las personas participantes, fue la adaptación de las actividades a las distintas necesidades que tienen las personas con discapacidad intelectual. Al mismo tiempo, se indican otros factores determinantes para realizar las actividades, es por ello que la falta de recursos figura como el segundo inconveniente más nombrado (citado por dos personas), junto al número de personas por taller (citado por otras dos); característica también ligada a la falta de recursos, en esta ocasión, humanos o a la falta de formación específica.

Respecto a las ventajas y los aprendizajes a destacar en las personas con discapacidad intelectual cuando se interviene con ellas a través del arte, dos de las personas entrevistadas, mencionan el enriquecimiento personal; el mismo porcentaje de participantes, destaca las habilidades sociales; las demás ventajas y aprendizajes o valores que se han considerado pueden observarse en la Figura 4, algunas de ellas como la autoestima, el disfrute personal o la posibilidad de expresión. 
Figura 4

Ventajas de la utilización de la mediación artística

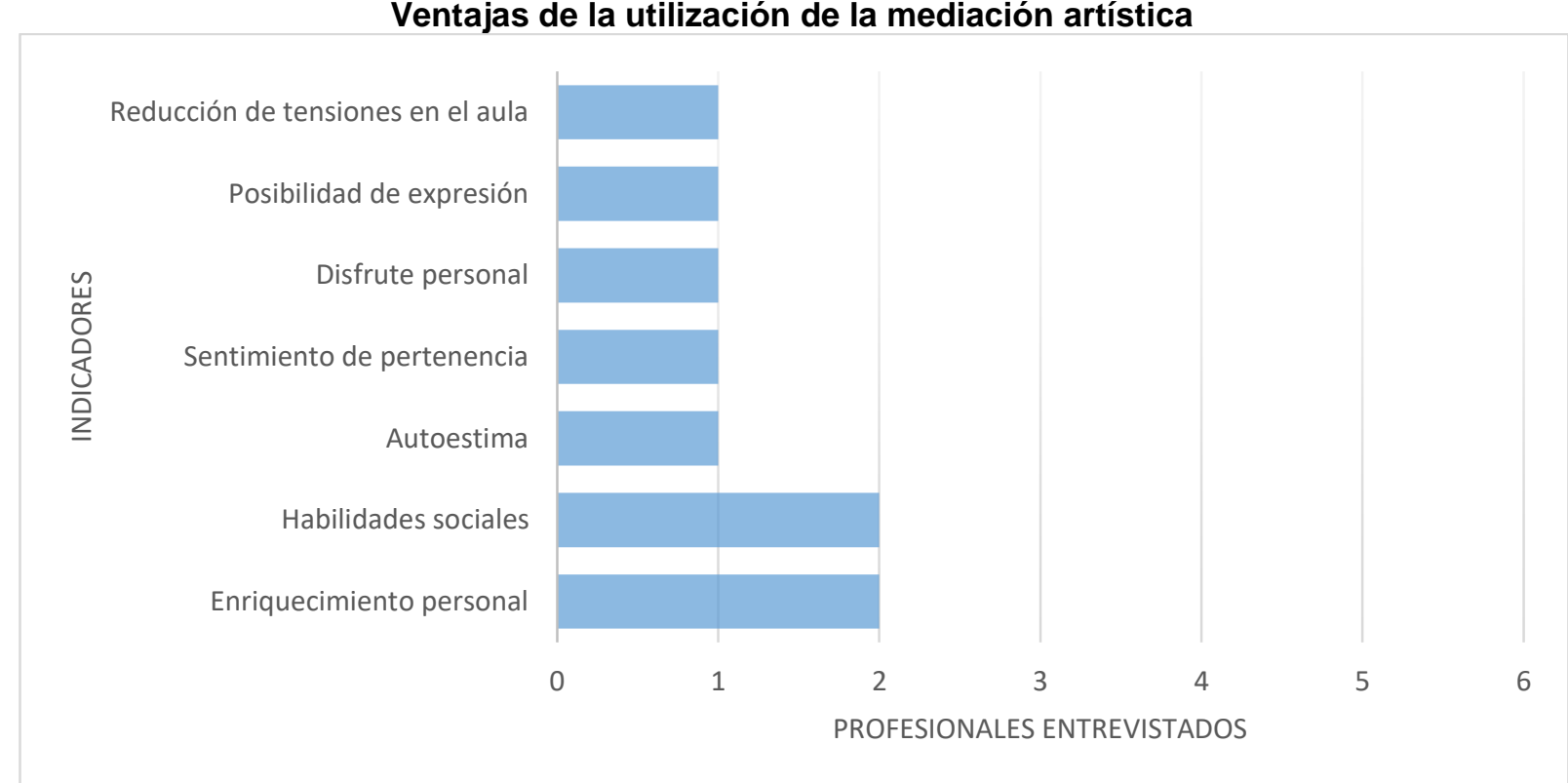

Fuente: Elaboración propia, 2016

Otra de las cuestiones evaluadas en la entrevista hacía referencia a la importancia de la participación e implicación de los familiares de las personas mayores con discapacidad intelectual. Sobre este aspecto, cuatro de las personas encuestadas opinan que la participación y/o implicación de los familiares es determinante a la hora de realizar cualquier actividad con las personas usuarias del centro, solo una de ellas considera irrelevante este papel. Asimismo, otra persona menciona el papel participativo de los familiares como algo muy interesante que se debería abordar en las distintas actividades del centro.

Finalmente, en cuanto a otras valoraciones o consideraciones ante las actividades de mediación artística, cuatro de las personas entrevistadas lo hace de manera muy positiva, salvo una de ellas que condiciona la valoración del taller o programa dependiendo de lo competente que sea la persona que lo imparta. En este último caso comentaba que esto podría tener relación con el hecho de si la persona que imparte el taller de mediación artística no lo hace de manera que persiga la filosofía del modelo de mediación artística, adoptando un rol de acompañante y guía durante el proceso de expresión y siendo capaz de enriquecer a las personas que participan en el taller cumpliendo con una ética profesional inclusiva que persiga valores democráticos, no se podrá valorar de forma positiva dicho taller. Igualmente la totalidad de las personas entrevistadas ha negado que la mediación artística sea una moda, y considera que siempre se ha utilizado como recurso pese a que en la actualidad se esté fomentando o dando mayor publicidad. 
Por último, cabe destacar que todas ellas consideran que los talleres de mediación artística gozarán de continuidad en el centro, de la misma forma que aumentarían la oferta de estos talleres. Al hilo de estas consideraciones, una de las personas reivindica la adaptación de los talleres al colectivo de personas mayores con discapacidad intelectual, mientras que otra reclama el fomento de la metodología de la mediación artística. Sin embargo, una de las personas entrevistadas alega que sus talleres pierden utilidad cuando emplean dicha metodología, refiriéndose a que el arte puede amenizar un taller que pretendía ser menos dinámico y más teórico, pero a la vez puede producir el riesgo de distracción durante el desarrollo del mismo, consiguiendo ese disfrute que aportan las distintas estrategias artísticas, pero no los objetivos y aprendizajes previstos, destacando como ejemplo el caso de los talleres de salud que se desarrollaban en el centro.

En la investigación se corrobora la importancia concedida a esta metodología para la intervención y aunque el nivel de conocimiento y formación que tienen en la utilización de esta metodología es diverso y en muchas ocasiones escaso, el nivel de concienciación respecto a sus beneficios en la promoción del envejecimiento activo es muy elevado. Por otro lado, el enriquecimiento personal junto a las habilidades sociales han sido los beneficios más nombrados por las personas encuestadas a la hora de hablar sobre las ventajas y aprendizajes de las personas mayores con discapacidad intelectual tras participar en talleres de mediación artística, ambas tan necesarias para el desarrollo de la autonomía y el fomento del envejecimiento activo (Shalock y Verdugo 2003, 2007; Morón, 2019).

La totalidad de los participantes en la investigación considera el arte como una herramienta imprescindible en la intervención socioeducativa y niegan que la mediación artística sea una moda. Además, está de acuerdo en que las adaptaciones de las actividades a las necesidades que presentan las personas mayores con discapacidad intelectual podría ser uno de los mayores inconvenientes, así como la falta de formación específica que tienen.

Importante también es su consideración sobre la participación e implicación de los familiares como un elemento a tener en cuenta a la hora de realizar cualquier actividad dirigida a las personas con discapacidad, algo que también las propias familias consideran (Guerrero, 2019).

Resulta interesante que las personas encuestadas relacionan el arte o la mediación artística con las actividades de expresión corporal, las de expresión plástica o manual y las actividades relacionadas con la música. Esto puede ser debido a la concepción más tradicional del arte y las obras artísticas, donde las principales disciplinas han sido la pintura, el teatro y 
la música, sin embargo, han destacado muchas más actividades dentro de dichas disciplinas y han indicado una amplia oferta de talleres que trabajan la mediación artística a través de distintos lenguajes.

Del mismo modo, han indicado que no existe una planificación y programación interdisciplinar de las actividades, ya que no coinciden en sus valoraciones en cuanto a diseño, tipo de contenidos o actividades y sistemas de evaluación e incluso en la consideración del rol a desempeñar. Igualmente, se precisa una adaptación de las actividades más acorde con un nuevo modelo de intervención que persiga el envejecimiento activo y se centre en la persona y sus necesidades (Limón, 2018). Asimismo, y recordando la definición de Sánchez y Pinazo (2007), el envejecimiento activo supone una manera de implicarse activamente en la vida, lo que implica conservar unas relaciones sociales satisfactorias y una actividad productiva que ayude a la mejora personal y de la comunidad.

La mediación artística o la intervención educativa a través del arte puede contribuir a la consecución de dos de los objetivos imprescindibles del envejecimiento activo según las OMS: la promoción de la autonomía y la calidad de vida. En este sentido, la mediación artística puede ser un modelo que contribuya a dicho fin, ya que fomenta la participación y expresión incondicional de las personas. El papel del arte no solo ayuda a romper con el estereotipo de las personas mayores con discapacidad intelectual, sino que también las acerca a la consecución de los objetivos que persigue el envejecimiento activo (Borja, 2013; Martínez y Rodríguez, 2015; Morón, 2019) especialmente del desarrollo socioafectivo, ya que favorece procesos de participación, comunicación e interacción social (Guerrero, 2015, p. 8).

\section{Conclusiones}

Es imprescindible tomar conciencia del aumento del porcentaje de personas mayores en nuestra sociedad, en especial, de las personas con diversidad funcional fundamentalmente, debido al aumento de su esperanza y calidad de vida como consecuencia de los servicios y prestaciones de una sociedad del bienestar. Por ello, este estudio examina la percepción del personal de atención directa a este colectivo con respecto a la utilización del arte en la intervención.

Teniendo en cuenta las consideraciones realizadas sobre el papel del arte para fomentar el protagonismo y la participación activa de las personas con discapacidad intelectual, y particularmente su contribución a algunos de los indicadores de calidad de vida (habilidades sociales, autodeterminación, autoestima...) (Alonso, 2016; Ballesta el al., 2011; Guerrero, 
2015), es fundamental avanzar en estudios que aborden la intervención que se está llevando a cabo.

De forma general, las personas encuestadas han considerado que estos modelos de la mediación artística o de la educación a través del arte suponen beneficios y ventajas para fomentar no solo la inclusión social, sino también la mejora de la calidad de vida y el desarrollo de un envejecimiento más activo, ya que fomentan aspectos como el desarrollo personal, la autoestima o la autonomía. No obstante, también han manifestado necesidades de formación, principalmente, en aspectos metodológicos y didácticos, y han afirmado que les gustaría recibir formación específica en la metodología de la mediación artística. Particularmente interesante es el debate o la reflexión sobre si es necesaria una formación artística mínima (Moreno, 2010). En cualquier caso, los resultados evidencian el alto interés por la formación de sus competencias para desarrollar programas y acciones relacionadas con la intervención a través del arte y la necesidad de incluir estas competencias en la formación inicial de los educadores y educadoras.

Las valoraciones del personal de atención directa a este colectivo son importantes no solo para identificar las necesidades formativas, sino también para la identificación de nuevas estrategias y acciones para intervención. Estas nos permitirán no solo establecer vías de actuación para la mejora y actualización de su formación, sino también para el desarrollo de nuevos enfoques para la intervención que tengan en cuenta estas aportaciones y modelos (Limón, 2018).

El nuevo desafío del envejecimiento activo de las personas con discapacidad intelectual debe ser de carácter social, ya que han de implicarse numerosas organizaciones para conseguirlo; impulsarse tanto políticas, como programas y prácticas dirigidas a este fin, que eviten la filosofía asistencialista y generen las herramientas y recursos necesarios para desarrollar la autonomía y no la dependencia.

Finalmente, en relación con las limitaciones de este estudio, el contar con una muestra mayor y la inclusión de perspectivas de otros agentes, entre otras, podría enriquecer y ampliar los resultados hallados. Igualmente, es necesario explicitar por ello que los resultados no son generalizables y son solo aplicables para la población estudiada. Asimismo, la inclusión de algunas de las reflexiones cualitativas aportadas por los participantes favorecería futuras investigaciones con diferentes tipos de datos y contextos.

No obstante, resulta esencial seguir investigando en esta nueva perspectiva para la intervención desde métodos mixtos que incluyan la propia perspectiva de las personas 
implicadas, así como desarrollar y evaluar programas específicos en esta línea que aporten evidencias científicas de sus resultados. Además, no se debe olvidar el importante papel que tiene la formación continua del personal técnico de los centros y cubrir sus necesidades de formación y cualificación: competencias y reconocimiento social (Guerrero, 2019).

A modo de conclusión, se podría decir que falta mucho camino por recorrer hacia la inclusión de las personas con diversidad funcional y el desarrollo de su envejecimiento de una manera más activa y saludable; para seguir dando pasos que no resten distancia, se ha de fomentar y apostar por herramientas que nos acerquen a conseguir dicho fin, tal es el caso de la utilización de metodologías más innovadoras como las relacionadas con la mediación y la intervención educativa a través del arte.

\section{Referencias}

Alonso, Dara. (2016). La educación artística en las personas con diversidad funcional. Habilidades bio-psico-sociales y calidad de vida (Tesis Doctoral). Universidad Complutense de Madrid, Madrid, España.

Amor, José Ramón. (2009). Calidad de Vida: la cuestión de los criterios. Síndrome de Down: Vida Adulta, 1, 72-77. Recuperado de http://www.down21.org/revistaAdultos/revista3/calidadvida.asp

Ballesta, Ana María., Vizcaino, Onil., y Mesas, Eva Cristina. (2011). El Arte como un lenguaje posible en las personas con capacidades diversas. Arte y políticas de identidad, 4, 137152. Recuperado de https://revistas.um.es/reapi/article/view/146051

Borja, Cynthia. (2013). Arte en la discapacidad: un doble beneficio. Revista Para el aula, (06), 24-25. Recuperado de https://aprenderly.com/doc/1506306/arte-en-la-discapacidad--undoble-beneficio

Berjano, Enrique., y Burgos, Evangelina. (2009). Discapacidad intelectual y envejecimiento: Un problema social del siglo XXI. FEAPS. Recuperado de https://sidinico.usal.es/documentacion/discapacidad-intelectual-y-envejecimiento-un-problemasocial-del-siglo-xxi/

Calderón, Ignacio. (2014). La participación de personas con discapacidad a partir del arte y la comunicación cultural. Aularia, 2, 43-46. Recuperado de https://dialnet.unirioja.es/servlet/articulo?codigo=4753779

Carrascal, Silvia., y Solera, Eva. (2014). Creatividad y desarrollo cognitivo en personas mayores. Arte, Individuo y Sociedad, 26(1), 9-19. doi: https://doi.org/10.5209/rev ARIS.2014.v26.n1.40100 
Carratalá, Ana. (2012). Un envejecer centrado en la persona. Envejecimiento activo y discapacidad. Claves para un servicio de calidad. Águilas: Universidad Internacional del Mar. Recuperado de https://edit.um.es/campusdigital/2012/07/18/

Comité Español de Representantes de personas con Discapacidad (CERMI). (2012). El envejecimiento de las personas con discapacidad. Documento de posición del CERMI Estatal (Borrador). Recuperado de http://envejecimiento.csic.es/documentos/documentos/cermiborradorenvejecimientoactivo-01.pdf

De Miguel Badesa, Sara. (2006). Las terapias alternativas como medidas de prevención y promoción de la calidad de vida. En Gloria Pérez-Serrano, Intervención y desarrollo integral en personas mayores (pp. 185-216). Madrid: Universitas S.A.

Eisner, Elliot. (1995). Educar la visión artística. Barcelona: Paidós

Etxeberría, Xabier. (2005). Aproximación ética a la discapacidad. Bilbao: Universidad de Deusto. Recuperado de https://www.cedd.net/redis/index.php/redis/article/view/433

Guerrero, Catalina. (2010). Procesos de envejecimiento en personas con discapacidad intelectual: una propuesta integradora. Enlace en Red, (15), 22-30. Recuperado de http://sid.usal.es/idocs/enlace/num15/enlace15.pdf

Guerrero, Catalina., y Martínez, M.a Zaida. (2014). Intervención con personas mayores a través del arte. En María Paz Araceli García y María Luisa Belmonte (eds.). Retos Educativos actuales en la formación del profesorado (pp. 23-31). Asociación Universitaria de Formación del Profesorado y Editum, Servicio de Publicaciones Universidad de Murcia. doi: 10.6018/editum.2862

Guerrero, Catalina. (2015). Arte, Mayores y Discapacidad. Arte diverso para capacidades diversas. En M. José Marín Pérez, Piedad Fernández Toledo, Virginia Villaplana Ruiz, M. Mar Grandío Pérez (eds.), Alfabetizaciones, transalfabetización e inteligencias múltiples: el componente transversal en el aprendizaje y las pedagogías críticas (pp. 118). Murcia: Universidad de Murcia. Recuperado de https://www.researchgate.net/publication/324605670 Arte Mayores y Discapacidad Arte diverso para capacidades diversas

Guerrero, Catalina. (2019). Indicadores de envejecimiento en personas con discapacidad. La percepción de las familias. European Journal of Child Development, Education and Psychopathology, 7(1), 59-72. doi: https://doi.org/10.30552/ejpad.v7i1.89

Helduakadi. (2014). Informe sobre Estereotipos asociados a las Personas Mayores. País Vasco: Red Social por un Plan Integral de Participación de las Personas Mayores en Euskadi. Recuperado de https://www.helduakadi.eus/wp-content/uploads/2012/11/2LIBRO envejecimiento\%20activo-cast.pdf

Hernández-Pina, Fuensanta., Maquilón, Javier., y Cuesta, José Daniel. (2008). El proceso de investigación y el análisis de datos en ciencias sociales. Murcia: DM. 
Instituto de Mayores y Servicios Sociales (IMSERSO). (2002). Envejecer en España. II Asamblea Mundial sobre el Envejecimiento. Madrid: Ministerio de Sanidad, Política Social e Igualdad. Secretaría General de Política Social y Consumo, IMSERSO. Recuperado de https://www.imserso.es/InterPresent1/groups/imserso/documents/binario/8088 8089 libr oblancoenv.pdf

Instituto de Mayores y Servicios Sociales (IMSERSO). (2018). Base estatal de personas con valoración del grado de discapacidad. Madrid: Ministerio de Sanidad, Política Social e Igualdad. Secretaría General de Política Social y Consumo, IMSERSO. Recuperado de https://www.imserso.es/InterPresent1/groups/imserso/documents/binario/bdepcd 2018. $\underline{\text { pdf }}$

Instituto Nacional de Estadística (INE). (1999). Encuesta sobre discapacidades, deficiencias y estado de salud. Madrid: Subdirección General de Difusión Estadística. Recuperado de https://www.ine.es/prodyser/pubweb/discapa/disctodo.pdf

Limón, María Rosario. (2018) Envejecimiento activo: un cambio de paradigma sobre el envejecimiento y la vejez. Aula Abierta, 47(1), 45-54. Recuperado de https://dialnet.unirioja.es/descarga/articulo/6292831.pdf

Losada, Andrés. (2004). Edadismo: consecuencias de los estereotipos, del prejuicio y la discriminación en la atención a las personas mayores. Algunas pautas para la intervención. $\quad$ Recuperado http://www.imsersomayores.csic.es/documentos/losadaedadismo-01.pdf

Madrigal, Ana. (2007). Envejecimiento de las Personas con Discapacidad Intelectual. Boletín sobre el envejecimiento, 26, 2-32. Recuperado de https://www.imserso.es/InterPresent1/groups/imserso/documents/binario/boletinopm26. $\underline{\text { pdf }}$

Martínez, María., y Rodríguez, Jesús. (2015). Arte y salud Social. Programas de participación sociocultural para personas con diversidad funcional. Revista española de discapacidad, (3), 125-131. Recuperado en https://www.cedd.net/redis/index.php/redis/article/view/201

Martínez-Salanova, Enrique. (2014). Educomunicación. La expresión inclusiva. Aularia, 2, 1-8. Recuperado de https://www.aularia.org/Articulo.php?idart=173\&idsec=1

Morón, Mar. (2012). La importancia de la creación artística en la educación de las personas con discapacidad intelectual. En Manuel Olveira y Carolina Pérez (Coord.), Encuentro. Artes por la integración (pp. 75-87). A Coruña: Diputación de Galicia.

Morón, Mar. (2019). La creación artística en la educación de las personas con diversidad funcional: Una investigación-acción. Didacticae, 6, 37-52. Recuperado de file://C:/Users/xtini/Downloads/28024-67537-1-PB.pdf

Moreno, Ascensión. (2010). La mediación artística. Un modelo de educación artística para la Intervención Social a través del arte. Revista Iberoamericana de Educación, 52(2),1-7. Recuperado de https://rieoei.org/historico/expe/3422Moreno.pdf 
Moreno, Ascensión. (2016). La mediación artística. Barcelona: Octaedro.

Navas, Patricia., Uhlmann, Sonja., y Berástegui, Ana. (2014). Envejecimiento activo y discapacidad intelectual. Madrid: Secretaría General Técnica. Centro de Publicaciones. Ministerio de Educación, Cultura y Deporte. Recuperado de http://envejecimiento.csic.es/documentos/documentos/Ministerioeducaciondiscapacidad-envejecimientoactivo-01-2015.pdf

Organización Mundial de la Salud. (2002). Envejecimiento Activo. Ginebra: Autor. Recuperado en https://apps.who.int/iris/bitstream/handle/10665/186466/9789240694873 spa.pdf;jsessi onid=6C54981DFFE69722ECDF467E2D3C271D? sequence $=1$

Pérez, Ramón. (2002). Prólogo. En Ramón Pérez (Ed.), Hacia una cálida vejez: Calidad de vida para la persona mayor con retraso mental (pp.11-16). Madrid: FEAPS. Recuperado en https://sid-inico.usal.es/documentacion/hacia-una-calida-vejez-calidad-de-vida-parala-persona-mayor-con-retraso-mental/

Pérez, Mónica. (2002): La Educación a través del arte en la Educación Social. Revista Pedagogía Social, (9), 287-298. Recuperado de http://www.redalyc.org/articulo.oa?id=135018332015

Pinazo, Sacramento., y Sánchez, Mariano. (2005). Gerontología. Actualización, innovación y propuestas. Madrid: Pearson Prentice-Hall. Recuperado en https://revistes.ub.edu/index.php/Anuario-psicologia/article/view/8597

Read, Herbart. (1991). Educación por el Arte. Buenos Aires, Argentina: Paidós.

Palacios, Agustina., y Romañach, Javier. (2006). El modelo de la diversidad: la bioética y los derechos humanos como herramientas para alcanzar la plena dignidad en la diversidad funcional. Madrid: Diversitas ediciones.

Shalock, Robert., y Verdugo, Miguel Ángel. (2003). Calidad de vida. Manual para profesionales de la salud, educación y servicios sociales. Madrid: Alianza.

Schalock, Robert., y Verdugo, Miguel Ángel. (2007). El concepto de calidad de vida en los servicios y apoyos para personas con discapacidad intelectual. SIGLO CERO Revista Española sobre Discapacidad Intelectual, 38(224), 21-36. Recuperado en https://www.plenainclusion.org/sites/default/files/224 articulos2.pdf 


\section{Anexo1}

\section{Cuestionario sobre la percepción de los profesionales acerca de la metodología de la}

\section{mediación artística}

El presente cuestionario pretende conocer la percepción y necesidades de formación de distintos profesionales que trabajan con personas mayores con discapacidad intelectual, en cuanto a la metodología de la mediación artística y la utilización del arte. Para ello, rogamos que conteste con sinceridad los siguientes ítems, marcando la casilla que corresponda al número que considere más oportuno según la siguiente valoración. Sus respuestas se tratarán de forma confidencial:

\section{1: nada; 2: poco; 3: bastante; 4: mucho}

\begin{tabular}{|c|c|c|c|c|}
\hline B1. Conocimiento de la metodología de la mediación artística & 1 & 2 & 3 & 4 \\
\hline 1. Conozco la metodología de la mediación artística & & & & \\
\hline $\begin{array}{l}\text { 2. He empleado la metodología de la mediación artística o utilizado } \\
\text { distintos lenguajes artísticos en mi trabajo }\end{array}$ & & & & \\
\hline $\begin{array}{l}\text { 3. En mi trabajo he diseñado o participado en actividades que utilizan } \\
\text { distintos lenguajes artísticos como pintura, música, danza, etc. }\end{array}$ & & & & \\
\hline $\begin{array}{l}\text { 4. Pienso que son necesarios y muy útiles los talleres y/o actividades } \\
\text { que trabajan desde la perspectiva artística }\end{array}$ & & & & \\
\hline $\begin{array}{l}\text { 5. En mi centro existe una oferta de talleres y/o actividades que utilizan } \\
\text { el arte como mediador de procesos de inclusión social }\end{array}$ & & & & \\
\hline $\begin{array}{l}\text { 6. Los talleres que utilizan el arte como herramienta valoran el proceso } \\
\text { de aprendizaje más que el resultado estético }\end{array}$ & & & & \\
\hline $\begin{array}{l}\text { 7. La metodología de la mediación artística debe partir de las } \\
\text { capacidades de cada individuo y trabajar con las mismas }\end{array}$ & & & & \\
\hline $\begin{array}{l}\text { 8. Para trabajar y/o participar en actividades de mediación artística, se } \\
\text { precisa de unas dotes artísticas mínimas y cierto conocimiento sobre el } \\
\text { arte }\end{array}$ & & & & \\
\hline $\begin{array}{l}\text { B2. Beneficios o ventajas de la utilización de la metodología } \\
\text { de la mediación artística }\end{array}$ & 1 & 2 & 3 & 4 \\
\hline $\begin{array}{l}\text { 9. Considero que la metodología de la mediación artística o la utilización } \\
\text { del arte es una herramienta adecuada para trabajar el desarrollo de } \\
\text { personas con discapacidad intelectual }\end{array}$ & & & & \\
\hline $\begin{array}{l}\text { 10. Las habilidades sociales son un punto clave en el desarrollo de dichas } \\
\text { personas y pienso que la mediación artística puede fomentarlas }\end{array}$ & & & & \\
\hline $\begin{array}{l}\text { 11. Entiendo la participación social como un factor importante a la hora de } \\
\text { determinar la calidad de vida de las personas mayores con discapacidad } \\
\text { intelectual }\end{array}$ & & & & \\
\hline $\begin{array}{l}\text { 12. Dicha metodología es un vehículo de comunicación que favorece la } \\
\text { expresión de las personas mayores con discapacidad intelectual }\end{array}$ & & & & \\
\hline
\end{tabular}


13. Opino que la metodología de la mediación artística aporta beneficios en el desarrollo de la autonomía de las personas con discapacidad intelectual

14. Creo que esta metodología podría ayudar a fomentar un envejecimiento activo

15. La mediación artística es una metodología adecuada para trabajar con personas mayores con discapacidad intelectual

16. La realización de talleres basados en la metodología de la mediación artística contribuyen a una mejora en la calidad de vida y bienestar de las personas con discapacidad intelectual

17. Creo que la metodología de la mediación artística es muy adecuada para favorecer y potenciar su desarrollo emocional

18. La metodología de la mediación artística es susceptible de adaptarse a cualquier contenido o competencia que se quiera trabajar

19. Considera que la utilización de la metodología de la mediación artística o del arte está suficientemente valorada en el ámbito educativo y social

20. Creo que la utilización de la metodología de la mediación artística o del arte es una metodología muy limitada para la intervención en este ámbito

\section{B3. Necesidades de formación \\ 21. En mi lugar de trabajo, los profesionales que imparten talleres de mediación artística cuentan con formación específica para ello}

22. He realizado algún tipo de formación en mediación artística o temas relacionados

23. Me siento capacitado para diseñar y dinamizar talleres que trabajen la metodología de la mediación artística o que utilicen el arte como estrategia para la intervención socioeducativa

24. Pienso que las estrategias para trabajar la mediación artística son accesibles a cualquier persona con independencia de su formación

25. Considero necesaria la formación específica en metodologías de mediación artística

26. Pienso que cualquier perfil profesional puede realizar un taller de mediación artística

27. Creo que la mediación artística debería contemplarse en el currículo de carreras universitarias como Educación Social, Pedagogía, Psicología, etc.

28. Me siento cómodo cuando empleo la metodología de la mediación artística o la utilización del arte

29. Me considero una persona creativa

30. Me gustaría recibir una formación específica en este tipo de metodología 
Revista indizada en

scip/o

redalyc satindex

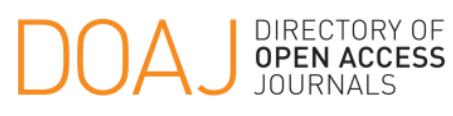

Distribuida en las bases de datos:

- Dialnet

O̊ SHERPA/RoMEO

REDIB

Red Iberoamericana

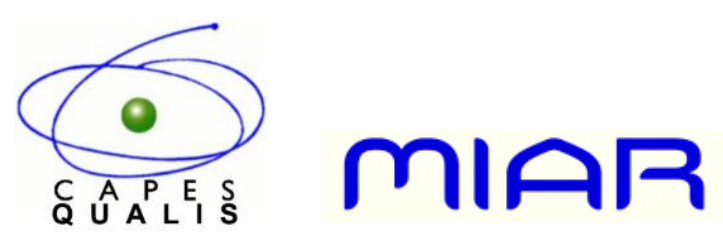

